\title{
Resolution concerning the participation of psychiatrists in executions
}

1. The College supports the World Psychiatric Association's Declaration on the Participation of Psychiatrists in the Death Penalty, approved at the Association's General Assembly in Athens in 1989.

2. The College will support psychiatrists working in countries where executions are still legal, who come into conflict with authority on ethical grounds concerning their involvement in executions.

3. The College recommends that psychiatrists confronting such difficult decisions bear in mind the following guidelines.

4. It is essential that the law, and citizens in conflict with the law, are provided with highly-qualified, well-trained and ethically sophisticated psychiatrists, most of whom will be working in the field of forensic psychiatry.

The College draws attention to the divisive effects on the medical profession of there being a death penalty. In relation to psychiatry, this is likely to lead to a withdrawal from the field of some of the most skilled practitioners, with damaging consequences for those persons who require assessment under the appropriate legal system.

\section{GUIDELINES \\ 1. Legal proceedings before and during trials}

The various stages of activity in criminal proceedings which may result in the imposition of a death sentence are:

(i) investigatory

(ii) assessment of fitness for trial

(iii) assessments to enable legal authorities to produce an appropriate verdict.

The College recognises that, in some circumstances, individual psychiatrists may refuse to give an expert opinion on criminal responsibility and like matters, if they feel that such an opinion would make it more likely that the person concerned would be found guilty and executed.

\section{Post-sentencing}

The activities in which psychiatrists may be required to participate after a sentence of death has been imposed are:

(i) therapy of persons awaiting execution (ii) the execution process itself

(iii) confirmation of death.

\section{Therapy}

A psychiatrist can and should treat a person on a voluntary basis who requires psychiatric care while awaiting execution. The provision of involuntary care is much more problematic and should generally only be undertaken if the psychiatrist has obtained a legal guarantee that the patient has had his or her sentence commuted. Each case should be decided by the psychiatrist according to his/her judgement in the circumstances.

On no account should the psychiatrist agree to state, after treatment, that that person is fit for execution.

Treatment should never be given for the purpose of co-operating in, or expediting, the execution process.

\section{Execution}

A psychiatrist should take no part whatsoever in the actual process of execution.

On no account should a psychiatrist give any opinion at this stage which states that person is fit for execution.

\section{Confirmation of death}

A psychiatrist should not confirm the death of an executed person.

The College recognises that participation at any of these stages may lead to ethical conflicts, which can only be decided by individual psychiatrists according to their conscience.

The College will give such psychiatrists strong individual support wherever they may work, if their decisions brings them into conflict with their colleagues or with other authorities.

\section{Recommendation to the Royal College of Psychiatrists}

The College should seriously consider making a statement opposing capital punishment. This should be done, if possible, in co-operation with the British Medical Association and with other Medical Royal Colleges.

Special Committee on Unethical Psychiatric Practices Approved by Council, 18 March 1992 